\title{
Projects for Special Purposes: A Progress Report
}

\author{
Andrew Edward Finch \\ Teachers' College, Kyungpook National University \\ Buk-Gu, Daegu, Republic of Korea 702-701
}

Tel: 82-539-505-832 E-mail: aef@knu.ac.kr

Received: January 4, 2012

Accepted: January 16, 2012

Published: March 15, 2012

doi:10.5430/wjel.v2n1p2

URL: http://dx.doi.org/10.5430/wjel.v2n1p2

\begin{abstract}
This paper reports on the design and implementation of project-based university Freshman English task-based syllabi by the author in Korea and describes further research, modifications and evaluations that have taken place since implementation of the original syllabus. The aim is not to justify the task-based and project-based approaches, but to report on the efficacy of these particular syllabi and the associated programs as perceived by teachers, students and other researchers. Having described some situations in which the syllabi have been incorporated, the paper concludes that a democratically-oriented project-based approach to foreign language learning offers a means of developing positive affect, autonomy, critical thinking, organization, and language skills in the context of the learners' major studies, as well as social skills acquired through collaboration and is therefore a pedagogically sound option for language teachers who wish to address contemporary challenges of smart technology and the Academic-English needs of their students. It is further argued that projects offer a strategy for language teaching through which traditional ethics can be combined with modern learning theory.
\end{abstract}

Keywords: Program evaluation, Task-based, Project-based, EFL, College, University, Freshman English, Asia

\section{Introduction}

No problem can be solved from the same consciousness that created it. We have to learn to see the world anew. (Albert Einstein)

Based on the recognition that a high-technology global economy cannot be served by an education system or by teaching methods designed to meet the needs of the Industrial Revolution, many commentators have espoused educational reform and new teaching paradigms. As Dryden and Voss point out:

Twenty-first-century multimedia literacy is not the same as old-style reading-and-writing literacy. Today's youngsters grow up in a society whose basic communication 'tools" are not the same as their parents' or teachers'. And schooling, to be effective, has to build on those differences. (Dryden \& Voss, 2005, p. 29)

The authors derive from this argument a need to change from transmissive to transformative learning, and in doing so, advocate "a more intelligent, subtle, whole view of learning and education. One that builds from humanistic educational approaches in the past, but also takes full account of new developments relating to complexity theory, systems theory, learning theory and the pressing imperatives of sustainability" (Dryden \& Voss, 2005, p. 14). This combination of traditional humanism with contemporary developments is particularly relevant for this paper, as a possible feature of the project-based approach. Hicks also identified this 'rear-view-mirror' (Note 1) problem when commenting that the world for which education is preparing students no longer exists: "If all education is for the future then the future needs to be a more explicit concern at all levels of education" (Hicks, 1994, p. 23), while Gardner (1993, p. 145) proposed the solution of a single criterion for effective education: "an education that yields greater understanding in students" (Note 2), a definition of effectiveness which provides a useful perspective on language education, where students are all too often unable to apply the learning they have acquired to real-life situations.

These findings are not new to language instructors in the 21 st century, many of whom would welcome the opportunity to bring smart technology, e-learning and contemporary language learning theory into their classrooms and to place it in a humanistic setting, but find their hands tied to an inflexible curriculum, an inappropriate textbook, or the requirement to prepare students for high-stakes tests. Acknowledging this situation, this paper builds upon the findings of earlier ones and suggests that a project-based approach to English Language Teaching (ELT) at university level in Korea has been shown to be sufficiently flexible and theoretically sound either to be incorporated into an existing framework or to stand by itself as a 
structure within which the future learning needs of the students can be satisfactorily met, while also attending to the multitude of affective factors that can impede learning.

Before discussing the outcomes of the programs involved in this report, it should be noted that literature reviews and rationales for the syllabi discussed in this paper are available in Finch 2007 and Finch \& Sampson 2001, in addition to the review of the process paradigm in Finch 2010, and are therefore not mentioned in this paper. In-depth discussions of the project-approach in ELT are also available in Beckett \& Slater (2005), Legutke \& Thomas (1991), McGovern (1995), and Stoller (2002). The relevant programs are also presented here in outline rather than explained in detail, since this paper essentially reports on findings subsequent to Finch 2001a, 2007 and Finch \& Sampson 2001, and on the efficacy of the principles and theories implemented in those studies. Interested readers are therefore referred to the earlier papers and to the online Student Workbooks and Teacher's Resources available at http://www.finchpark.com/books/twa and /books/u2u. It should suffice to mention here that subsequent to initial attempts at a project-based component of a three-year conversation program (Section 3.1) the main focus of this paper is on the second attempt (Section 3.2), in which the researcher co-authored a syllabus (along with teaching/learning materials) for a Freshman English program, choosing the project-based learning format as one which would offer the greatest freedom to the teachers and the students, while offering opportunities for self-directed success and fulfillment in terms of acquiring English for Specific Purposes (ESP) and English for Academic Purposes (EAP) in a democratic, conversation-based environment. The third and fourth versions (Sections 3.3 and 3.4) build upon this second program and its core syllabus. In the third, the Workbook was incorporated into three university credit courses in Korea, while in the fourth, independent researchers adopted the syllabus for university engineering students in a Japanese university.

\section{Overview: The Situation}

With two hours per week of student/teacher contact time, spread over two semesters of 15 weeks, students on university or college English conversation courses in Korea can look forward to a maximum of 60 classroom hours in an academic year. In reality, this teacher-directed learning time is reduced by mid-term and final exams, national holidays, 'Membership Training' (student-led initiation camps), and student festivals (not to mention sickness) so that 50 hours is a more realistic estimate. Given that "Intensive EFL course providers estimate that 300-400 hours of study are required to rise one IELTS level" (Graddol, 2007, p. 96) and that the recommend number of hours of tuition needed to move up a level on the Common European Framework of Reference for Languages (CEFR) is 200 hours (except at beginner level, Table 1), it could be concluded that most Freshman students, who have usually achieved at least A1 or A2 level (Note 3) by the time they enter university, would need four years of university study in order to show any noticeable progress. This might seem to be an impossible situation for the language instructor, since it would appear that measurable improvement in target-language proficiency is impossible over one semester (25-30 hours) and even over one academic year (50-60 hours), by definition. However, when it is taken into account that Korean Freshmen can be classified as false beginners, having studied English from elementary school to high school, in addition to all the hours spent at private language institutes or with private tutors (Note 4), it becomes evident that expectations are different from those in which students are new to the target language.

\section{<Table 1 about here>}

Students who attend university courses in Korea have studied English as a means of preparing for high school entrance and for the university entrance test (College Scholastic Ability Test), which requires extensive knowledge of English grammar and vocabulary, to the exclusion of performance skills (speaking and writing) (Note 5). They have often forgotten much of what they learned, though this is normal when the goal of passing a high-stakes, utilitarian test (in particular those featuring multiple-choice, language-as-code, discrete items) has been achieved (Note 6). Thus students entering a Freshman English course often share an inability to communicate in the target language, though some possess surprising amounts of lexis which can be accessed even in the restricted timeframe of two hours per week. University English programs can therefore presume a database of grammar and vocabulary as a starting point, so that the task of the instructor is to focus on under-developed performance skills, while 'filling in the gaps' in proficiency.

Or is it? Such a deduction as the one in the previous sentence contains assumptions regarding the purpose of Freshman English courses, as well as ignoring the affective barriers to learning (lack of confidence, low motivation, test-anxiety, negative attitudes) which students typically bring to the classroom after years of test-preparation (Hashimoto \& Fukuda, 2011, p. 17) and falls into the trap of generalizing from insufficient data, while ignoring the innumerable independent and dependent variables that typically frustrate language programs at 'ground level' (in the classroom). In this context, it is worth noting that the goal of employing native speakers as instructors (rather than the many well-qualified bilingual Koreans available) is not to repair deficiencies in grammar or lexis. When dealing with false beginners it must be remembered that even those who are completely lacking in the basics have not become so as a result of a lack of tuition. On 
the contrary, they have been studying English for the whole of their educational careers and have somehow managed not to learn what they have been taught (perhaps their learning styles differ to those of the teachers, or they see no reason for learning a second language). To attempt to redress this situation by 'teaching' them the same content is therefore an insult to their previous teachers and to the students themselves. Rather, a different approach is needed in order to (re)ignite the flames of motivation that have been doused by an autocratically (Note 7) situated test-preparation approach.

This brings us to the purpose of university English courses - one that is often hidden behind textbooks designed for ESL students and career-oriented high-stakes tests such as the Test of English for International Communication (TOEIC). While this purpose is rarely outlined in university policy documents or given concrete form in terms of an in-house language program (Kroeker, 2009), Sterling (2002) points out that the pendulum of educational policy around the world tends to swing around four main attractors (Note 8):

1. To replicate society and culture and promote citizenship - the socialization function;

2. To train people for employment - the vocational function;

3. To develop the individual and his/her potential - the liberal function; and

4. To encourage change towards a fairer society and better world - the transformative function. (Sterling, 2002, p.25)

These four goals can be found in the official educational policy of Korea, as presented in the UNESCO World Data review of 2006, though the liberal function (number 3, above) appears to take precedence:

The objectives of Korea's education, under the ideal of Hongik-Ingan, the founding philosopher [sic] of Korea, are to help all people perfect their individual characters, develop the self-sustaining ability to attain independent lives, acquire the qualifications of democratic citizens, participate in the makings of a democratic state and promote the prosperity of all humankind. (UNESCO, 2006)

Such a humanistic view of education is at the heart of traditional education in Korea (Gee, Choi-Wan, 2006, pp. 13, 15) but can also be traced back to U.S. school systems in the 17th century, when it was held that the studies that develop human intellect are those that make humans 'most truly human'. The practical basis for this was faculty psychology, or the belief in distinct intellectual faculties, such as the analytical, the mathematical, the linguistic, etc., somewhat akin to recent interest in the concept of Multiple Intelligences (Gardner, 1983). Strengthening one faculty was believed to benefit other faculties as well (transfer of training). Major humanistic texts have been written by authors such as Matthew Arnold, Irving Babbitt, I. A. Richards, Thomas Dewey, Alfred North Whitehead, Robert Hutchins, T. S. Eliot, C. P. Snow, F. R. Leavis, and his American counterpart, Lionel Trilling (Spanos, 1985) and more recently by philosophers such as Krishnamurti, who presents a rationale for education in terms of individual growth:

Though there is a higher and wider significance in life, of what value is our education is we never discover it? (...) as long as education does not cultivate an integrated outlook on life, it has very little significance. (Krishnamurti, 1981, p. 11)

To understand life is to understand ourselves, and that is both the beginning and the end of education. (Krishnamurti, 1981, p. 14)

Postman (1995) also offers a humanistic perspective:

Schooling can be about how to make a life, which is quite different from how to make a living. Such an enterprise is not easy to pursue, since our politicians rarely speak of it, our technology is indifferent to it, and our commerce despises it. Nonetheless, it is the weightiest and most important thing to write about. (Postman, 1995, p. x - foreword)

This statement points to the inadequacies of the instrumental or vocational view of education (number 2 in Sterling's list, above), which is predominant in terms of practicalities (rather than policies) in Korea and many other countries around the world. It is a commonplace of observation that high school students in Korea are subject to grueling courses of study in schools and private institutes (Gee, Choi-Wan, 2006, pp. 11-12) and that teachers do not have time to attend to holistic goals such as creativity, higher-order thinking skills and personal development, while tied to the demands of test-preparation. Recognizing the gravity of the test-driven situation in his own country, Postman goes on to introduce the idea of themes - one which supports the use of projects, is central to the Montessori method and has been shown to be particularly effective in promoting the sort of responsible, intelligent individuals that are outlined in the UNESCO document (above):

Among the "new" ideas now current in several places is the organization of schooling around themes. This is a progressive idea, pointing as it does to the need for providing meaning in education. (Postman, 1995, p. 101) 
As can be seen from this brief outline, humanistic educational policies in Korea have had to co-exist with and even take second place to utilitarian or vocational considerations of supply and demand, which require secondary students to prepare for the high-stakes tests that represent the only gateway (for those who are not wealthy enough to bypass them) to educational and financial prosperity. One might hope that the stated goals of university English programs would place more emphasis on the socialization, liberal and transformative purposes (Sterling, 2002, p. 25), but the broad umbrella of 'Conversation English' that most universities shelter under does little to define the approach that might be taken by instructors, or the outcomes that might be expected. In fact, as Kroeker (Note 9) (2009) observes, "conversation is a title used to encourage speaking in class that may or may not be conversational in nature. This is because the main role is to prepare graduates for future employment where a TOEIC score tends to be required" (Kroeker, 2009, p. 45). Furthermore, "there is a high level of unstructured speaking related English themed classes with little accountability and immeasurable outcomes" (Kroeker, 2009, p. 46). Finally:

This study illustrates that conversation classes will continue to be divergent unless a consensus among ELT teachers and administrators is reached on defining these classes. This definition must be informed by details of government mandates that influence English language policies, the knowledge of constructs used in policy rhetoric, the uses of English in the Korean job market, the needs of the students, and the context that these classes are placed in. Once a definition has been established, then more consistency can be generated through goal setting and its assessment, valid testing, and appropriate course content. (Kroeker, 2009, p. 46)

This picture of 'general' (rather than 'conversation') English courses proceeding without sufficient direction or planning arises from Kroeker's research at one particular university in Korea, though the author's experience gained in the universities in this present study and through talking with instructors around Korea, would suggest that her conclusions are probably applicable to the majority of university language programs, with some notable exceptions. Given this lack of official direction, it might seem difficult to suggest an appropriate teaching approach. All that can be said is that such courses generally have the title 'conversation English', but they often turn out to be courses in informal English, survival English, or TOEIC preparation, depending on the focus of the particular textbook which has been prescribed by the administration and as such can have little benefit in terms of preparing students for the technical language that they will need in order to pursue professional development in their majors (Note 10). On the other hand, viewing the predicament from a different perspective, it could be said that such a lack of direction provides a certain starting point, since it offers a measure of freedom. Gardner (1993) has pointed out that language teachers are intelligent human beings and can generally 'get round' the textbook in a way that satisfies the students and the administration: "It is up to the ingenious educator to exploit constraints as well as to seek to circumvent them" (Gardner, 1993, p. 8). Such an attitude redefines restrictions and lack of direction as starting points from which to examine the needs of the students and also the broader goals of education. This was the attitude adopted in the programs under consideration, in which a project-based syllabus, either incorporated into an existing curriculum or standing by itself, was employed as a pedagogically sound and effective means of promoting positive affect and autonomy through a student-centered, self-directed approach, empowering students in the acquisition of the technical language required in their major fields of study, as well as providing for the development of 'conversational English'.

\section{Method: Projects in Practice}

Four locations form the basis of this report. The first two were National Universities in Korea, in which project-based learning was carried out in the Language Centers as part of the compulsory conversation English programs. In the first of these, the project-work took place in the third year of a three-year program, while in the second it formed the whole Freshman English program. The third location was also a National University, but the learners this time were students of the English Education Department (graduates and undergraduates) and the projects were incorporated into a number of credit courses. The fourth location was a university in Japan, where the project-based syllabus and other aspects of the second program such as the Class Journal (http://www.finchpark.com/ppp/Class_Journal/index.html) were adopted for a Freshman conversation course for Engineering students (Hashimoto \& Fukuda, 2011).

\subsection{Beginnings}

The first use of projects occurred from 1997 to 2000 in a three-year university English conversation program which used a task-based approach in years 1 and 2 (Finch \& Hyun, 2000a) and projects in the $3^{\text {rd }}$ year of study (Finch \& Hyun, 2000b). In-house course books were written for this program (Finch, 2001a; 2007; 2010; Finch \& Sampson, 2001) because of the unavailability of suitable, culturally appropriate and pedagogically sound texts for false-beginners. These books (and the teacher-books) were later put online for ease of access and can be downloaded without copyright restrictions from www.finchpark.com/books/zip. The third-year project-based text, The Way Ahead, was designed to be student-specific in its promotion of autonomy and learning skills. An initial 'learning-to-learn' pre-project section introduced relevant concepts and 
gave students opportunities for experiencing collaboration and for developing learning strategies, self-direction, and self/peer-assessment. This section led into eight project packs (Note 11), consisting of theme-related group activities, most of which could be developed, if wished, into language-learning projects. Failing this, suggestions for projects were offered in the final pages of each pack. Having worked through the 'learning-to-learn' pre-project section and having chosen a project to work on, students were ready to spend in-class and out-of-class time making projects. After a number of weeks of such teacher-supervised, self-directed work they then presented their projects in class and these presentations and their content were self-assessed and peer-assessed by their classmates.

The project packs were designed to supply the sort of language that students might need in working abroad or in working for foreign companies in Korea (presentations, meetings, public speaking), in addition to addressing the need to understand English newspapers and TV News broadcasts. In this sense, the goals were fairly general and did not address the technical language that students needed for their majors (e.g. medical, engineering, or legal vocabulary). However, feedback from the students and teachers indicated that this first attempt at a project-based learning experience was successful in a number of ways. Results of internal questionnaires and interviews (given to students and teachers) were very positive (Finch, 2010), while comments relating to the project-based component were also indicative of academic and personal growth. The following extracts from teacher interviews, which can be found in Appendices A-73 to A-88 of Finch, 2010, pp. 419-440, are introduced here to indicate general satisfaction with the project-based Junior course, but also to highlight aspects that were seen to be in need of revision.

Junior \& Sophomore students feel that they have improved in English. ... They came up with it [this observation] on their own.

Most of the [Junior] students said they were learning more.

Most of the [Junior] students do have good attitudes now. (...) Generally, they enjoy the projects.

One [Junior] group on their own chose to work through the activities. They're doing it on their own, and they're self-directed.

They see that they are directing it [the English class] and having fun.

The program ... does give you freedom. ... The book is just a guideline.

Junior program - impressed with the studentsee and teacherse book. (...) students had a problem with the meetings (...) once they got over the idea of meeting the teacher, these went well.

The Junior program is a good program, [though it] has some organizational bugs - need for debriefing about each project.

The [Junior] textbook needs re-arranging

The points raised in the last two of these comments were addressed in the second location, but before moving on to the second program, it is interesting to note that the first one was included in a university-administered student-feedback questionnaire given to students on all courses in all faculties. This questionnaire (Finch, 2010, pp. 416-417) contained 15 questions about the appropriateness of the program, the attitude of the teachers, the assessment methods, and the satisfaction of the students in terms of interest, achievement and course value. The program scored highly on this external evaluation in June and December 1998, these being the only student-feedback questionnaires given while the author was at the university. In fact, in both instances, the average score was the highest of all those recorded in the university, reaching 3.93 (June 1998) and 3.99 (December 1998), out of a possible maximum of 5.0. Such results, while vindicating the ethos and practicalities of the program in terms of student satisfaction, do not necessarily form the basis of comparison with other faculties, since the number of variables involved and the novelty of the language program at that time make such inferences invalid. However, it is significant that the program was found to be functioning well in terms of this independent evaluation and the findings offer valuable triangulation of the researcher's own internal evaluation. It must also be remembered that the university questionnaire included all three years of the program and that the project-based element was limited to the third of those years.

\subsection{Freshman Projects}

The previous reservations are not true of the second venture into designing a project-based one-year Freshman English program, which took place in a different university in Korea from 2003 (Note 12) to 2005. Once more, the student Workbook was designed by the program developers (Finch \& Sampson, 2004) to suit the learning needs of students who, as with most university English courses, came from all the departments in the university and required a working knowledge of the English that was used in their field, whether for the purpose of taking that knowledge abroad (studying or working), working in a foreign company in Korea, reading technical books about their subject, or accessing specific information on the Internet. 
Their need to use casual, conversational English (the apparent goal of many Freshman English programs) was small, compared with the ever-increasing need to be able to access technical information written in English, to interact in social and professional networks in English, and to take major courses which used English as the teaching medium. It was therefore considered, in the light of research such as Legutke \& Thomas (1991), that the acquisition of learning strategies and higher-order thinking skills through a project-based approach would empower students to acquire specific technical language, while having beneficial side-effects in terms of target-language use, participation, increased interest and motivation.

In the first half of the first semester, students focused on learning strategies and began to investigate the 6 project packs (Note 13) available in the Workbook (Note 14). After this, each group chose a project pack and made a pilot project, experiencing and developing the team-work and collaboration that they would need in the second semester, when they designed and presented their own projects, which were self- and peer-assessed, offering an opportunity to experience and benefit from self-reflection and formative feedback from their peers. In this way, presentation skills and assessment skills were promoted, alongside the creative, cognitive and social skills demanded of project work.

In contrast to the previous program, project-packs were now seen as springboards, giving the students the tools to create their own projects. They were still free to use the packs in the second semester, but it was hoped that those who felt confident to do so would jettison the Workbook and apply its principles to a project of their own making, preferably one which helped them to explore their own major and the specific English that they needed. Hence, having served its purpose, the textbook was seen a crutch, or an infrastructure, which could be discarded when it had fulfilled its purpose. This approach was in keeping with Postman's suggestion that:

We can improve the quality of teaching and learning overnight by getting rid of all textbooks. Most textbooks are badly written and, therefore, give the impression that the subject is boring. Most textbooks are impersonally written. They have no "voice," reveal no human personality. (Postman, 1995, p. 115)

Being able to go beyond the textbook, however valuable (or otherwise) it might seem, was an intrinsic part of the learning process and the development of autonomous learning skills, though it remained available as a support for those who felt unready to function without its guidance. This approach provided a number of advantages for teachers and students. Once the students were ready to make their own projects for their specific learning needs, it was felt that EAP and ESP teaching was really taking place. Teachers could not be expected to be proficient in the technical language of medicine, engineering, law or physical education, etc., but they could ask students to make their own major-related projects, in which students would find and use the special language related to their majors and give professional presentations on them. Teachers would then be able to focus on information-access, presentation skills and public speaking, while making the most of the opportunity to learn something from their students. Postman suggests that teachers can be more effective in such a situation than if they continue to transfer the limited knowledge which they have acquired in their own academic experiences.

Most teachers, especially high school and college teachers, teach subjects they were good at in school. (...) As a result they are not likely to understand how the subject appears to those who are not good at it. If, let us say, for a semester, each teacher were assigned a subject which he or she hated or always had trouble with, the teacher would be forced to see the situation as most students do, would see things more as a new learner than as an old teacher. (Postman, 1995, pp. 114-115)

Statistics are not available for this location (Note 15), though findings based on this syllabus are amply supplied in the discussion relating to the fourth location (section 3.4). It is necessary, therefore to rely on the reactions from the 15 teachers, some of whom voiced their concern at what they saw as 'shock and awe' learning tactics and were worried that their students didn't have the necessary organization skills to even begin on project work (Note 16). Much of the dissent that was voiced was "about surrendering control in the classroom" and "Objective goals about learner autonomy, self and peer evaluations, and higher order processing were disparaged" (Personal communication with the academic director of the program, August 2011):

Eventually most teachers settled down and reported positive experiences with U2U. Recall that we conducted workshops on several days introducing the textbook before it appeared in the classroom and teachers had the choice to abandon the programme at any time. Still fear took hold in the early going.

The strongest teachers (again, an opinion) quickly identified the high quality materials in U2U. They were very interested in the detailed programme for self and peer-assessments and student record-keeping. There were positive comments about the design, with everybody on the same page early on developing a base of learning experience, then later making choices, finally abandoning the textbook.

I think learners would benefit from some script writing tasks in the classroom. (...) More grammar and vocabulary input from the teacher to help polish the final product. I think this would be useful in term of 
language acquisition and also gives the teacher another opportunity to productively participate in all the projects. (Personal communication with the academic director of the program, August 2011)

One of the teachers on the program also provided valuable insights into the program from a distance of 8 years:

The Pre-Project Packs - I remember most groups spending around 8 classroom hours working on these. There are very accessible, combine writing with speaking and are repetitive enough to build confidence with even the most reticent language learners. I think these are crucial to creating a non-threatening environment and building classroom community. Also, with activities such as the 'My Language skills and Needs' self-assessments students begin to understand the width and depth of the language and see that, in many ways, all learners (in Korea anyway) already do have substantial English skills. Also, learners [see] the many ways that English does apply to their lives and is meaningful to them. I think maybe there could be actual student conversational work done with the learning concepts to achieve more early buy-in with the students. This might help ease the understanding of the goals of the course.

The Learning Contract - I think this is crucial to build community and enhance the idea that it really is up to you how much you get out of your learning and the course.

I remember finding the self-assessed conversations and READI charts challenging for the students. I do think it is an important self-awareness tool, but I remember students not putting as much thought into them as I would have liked. Or perhaps that was simply their ability at the time?

Project Packs - These worked well. Nicely scaffolded and I know most students felt empowered to complete the projects and present them. I think students usually completed two or three in any given semester. Maybe a final project would be for students to design their own project pack for the higher levels? (Personal communication with a teacher on the program, September 2011)

Thanks to such refection by the academic director and formative feedback from the teachers, portfolios were added to the program, helping the students to collect, collate and organize their work. The two 15-week semesters (two contact hours per week) gave students little time to make the leap from teacher-centered, memory-based learning to self-directed discovery learning, so comprehensive information and lesson content was made available online, allowing students to prepare for classwork and assignments (Note 17).

\subsection{Integration}

This last feature (online resources) was developed in the third location, also a National University in Korea, from 2004 to 2006. As already mentioned, the students were English Education students and the use of projects and online resources was in the manner of a meta-approach to language learning, since it showed them how a project-based course might function in secondary schools, in addition to getting them to experience the process paradigm inherent in the approach. In this way, students learned how to develop creativity, problem-solving, critical thinking and team-work skills, while learning English. Using the same Workbook and Teacher's Resources as in the second location, project-based learning was integrated into teacher-training courses, in a "Teaching Practical English" graduate course $\left(2004,2^{\text {nd }}\right.$ semester), an undergraduate course with the same title $\left(2005,1^{\text {st }}\right.$ semester), and a "Teaching Methodology" course $\left(2006,1^{\text {st }}\right.$ semester), showing that the project approach was flexible in its application in the classroom, that middle/high school learning goals could be achieved by this means, and that middle/high school textbooks could be supplemented using projects. In addition, course information, along with lesson materials, assignments and reference links were put online, so that students could prepare for and review classes and access lesson materials at any time. Webquests were also explored as an online alternative, providing an interesting and effective way for students to design their own projects.

As with the second location, anecdotal evidence indicates general student approval but with some important differences. First of all, the teacher was also the researcher and the author of the Workbook, so that oral feedback was not necessarily as reliable as in second and fourth locations, where the researcher was not involved in running the program. Secondly, the students viewed the Workbook content and the process-based approach from the perspective of pre-service and in-service teachers and because of this many were skeptical about its practical application in secondary schools, voicing an argument often heard in teacher-training seminars: "I'd love to do this in my classroom, but it's not possible". Despite this codicil, the philosophy behind the project-based approach and the need for developing higher-order thinking skills along with positive affect was largely understood and appreciated. This awareness was made evident in the end-of-semester online course evaluations performed by students prior to accessing their grades. As with the first location, these online evaluations (now in the form of an 18-point questionnaire) provided useful feedback, though the one for the 2004 course is no longer accessible. For the 2005 
Teaching Practical English course $(n=22)$, which scored 4.77 out of a possible 5.0 on these evaluations (well above the university average of 4.05 for that semester), the following scores were given:

1.01 The evaluation method [self/peer assessment] was appropriate. (Note 18) (4.76)

1.03 The textbook was appropriate for the goals of the course. (4.81)

2.03 The student's opinions were respected during the lessons. (4.67)

3.04 The assignments were appropriate for the goals of the course. (4.86)

4.01 The lessons were satisfactory and the goals of the course were achieved. (4.71)

Such scores, along with comments such as "The course goals were effectively put into action" would seem to indicate general student approbation. These were mostly replicated on The Teaching Methodology course (2006) (n=57), which scored 4.47 (University average 4.0), along with independent student comments:

Satisfied.

It went well as it had been planned.

Thank you for your passionate lectures.

Meticulous and well-organized!

Good job

A

\subsection{Independent research}

The comments at the end of the previous section prepare for discussion of the fourth location, in which the Workbook and its syllabus was adapted by researchers (Hashimoto \& Fukuda, 2011) to the needs of engineering students in the Japanese University of Tokushima. As Hashimoto and Fukuda point out, of three categories of instructors (autocratic, laissez-faire, and democratic), research has shown that groups of students led by democratic instructors "had the highest motivation and originality in their work and studied continuously even without the teacher present" (2011, p. 17). In this light, it is important to recognize that no methodology or approach is teacher-proof and that instructional styles and attitudes have a significant impact on "learning attitudes and motivation and their potential to change them" (2011, p. 18). As pointed out in the discussion on the second location, program designers can set up a program, but it is the teachers who carry it out and who adapt it to their teaching philosophies. If that program (as is the case of the project-based approach) is founded on student-centered principles of autonomy, self-esteem, and a non-threatening learning environment (Finch, 2001b), it should be no surprise if the desired outcomes are not achieved in a teacher-centered (autocratic), competitive environment, or even in a laissez-faire one. The student comments about a passionate approach and meticulous organization (end of section 3.3) are therefore very relevant, since they point to the ethos of the program being actively present in the facilitator.

The details of the program as it was implemented in Japan are available in Hashimoto \& Fukuda (2011) and the author of this paper is grateful to these researchers for providing quantifiable results to complement his own mixed-method ones. Without repeating the findings as they appear in the study, it seems apt to mention that using the same syllabus, the course focused on decreasing anxiety and increasing autonomy for the first six weeks, at which time short presentations were given on topics of the students' choice. There was no teacher intervention unless requested by the students. For the next six weeks students worked on themes of their own choice and gradually "adapted to learning autonomously while concentrating on both fluency and accuracy" (Hashimoto \& Fukuda, 2011, p. 18). As with The Way Ahead and It's Up to You!, The final three weeks were spent on rehearsals and final presentations. The concept of a Class Journal (CJ) was also adopted from the program of the second location.

Student feedback was collected through a four-point survey focusing on interest, active participation, achievement and satisfaction. There were 40 students on the project-based course, while students in two other courses $(n=42,40)$ were control groups and received the same survey. As can be seen in the report of the study, students on the project-based course scored significantly higher than the control groups in all four areas.

\section{$<$ Tables $2 \& 3$ about here>}

Based on their findings, the researchers concluded that:

A more democratic course centered on student choices and instructor facilitation showed positive results in learning attitude and motivation. Throughout the investigation, changes in students' attitude were observed, such as those discerned in CJ comments changing from negative to positive. Students' motivation seemed to increase, for example, when students started seeking opportunities for more English practice. (Hashimoto \& Fukuda, 2011, p. 21) 
Though the focus of the researchers was on the democratic aspect, their findings regarding positive attitude change are significant, showing the flexibility of the original program and confirming the need not only to address affective barriers but also to place language learning in an autonomous framework. The results of this study provide further evidence that a project-based university English program, when implemented in the spirit of non-threatening, facilitative, student-centered teaching, can successfully deal with the affective and linguistic issues that students bring to the classroom and help them to become autonomous learners.

\section{Conclusion}

Educational reform has become a popular topic for policy makers in East Asia (Mok, 2006) and a number of measures have been introduced in Korea at secondary level (Kroeker, 2009), though the outcome has usually taken the form of intensified reliance on standardized testing, with predictable demotivation on the part of teachers, who have become understandably reluctant to take on new approaches. In such an environment, in which top-down reforms have done little to change the attitudes or achievements of students and have simply increased the burden on teachers (in particular at secondary level), this paper suggests that project-based learning offers a student-centered, top-down (local language curriculum) and bottom-up (individual teaching approach) means of developing higher-order thinking skills at secondary and tertiary level, ultimately fostering the qualities to be found in 'the well-educated person'. It is also argued that the project approach, as outlined in the four locations described in this paper, has a number of benefits for teachers and students, including a lifting of workload from the former and increased responsibility for the latter.

Based on the contents of this report, it is suggested that findings of the studies so far carried out confirm the expectations of Finch \& Sampson made shortly after the implementation of the project syllabus in the first location (2001):

1. project syllabi are feasible in tertiary education in Korea;

2. projects encourage students to take responsibility for learning;

3. projects allow students to choose their own learning path (e.g. to learn how to give a presentation in English about an aspect of their major);

4. projects promote holistic learning, in that students are at the center of the learning process and are accountable for their achievements;

5. the teacher is freed from the role of language model, and becomes a learning resource and counselor;

6. assessment is by self- and peer-evaluation, which itself is a consciousness-raising experience, and which tends to be more meaningful and reliable than teacher-based assessment;

7. projects allow for process and product;

8. proficiency level is not a problem (beginners employ the L1 to a greater extent than advanced students);

9. projects allow students to learn whatever is relevant to them (the appropriate thing at the appropriate time for the appropriate student). (Finch \& Sampson, 2001, p. 12)

These findings result from research carried out in universities in Korea and Japan, but it is suggested that the benefits of the project-based approach are applicable at the secondary and even elementary level in Korea, as evidenced by the inclusion of project-based activities in school textbooks, the popularity of the iEARN (International Education and Resource Network) collaborative project network in Korea (Note 19) and the wealth of links to student projects (student-made movies, dramas, blogs, wikis, newspapers, etc.) on the Japan-based Internet TESL site: http://iteslj.org/links/ESL/Student_Projects/.

Whatever the pressures of modern education, including frequent reforms, mountains of administrative paperwork (in the case of secondary school teachers) and standardized tests, the need to address negative affect and to educate the whole person, while preparing students to live and work in a high-technology global economy cannot be ignored. As Wikis, Blogs, social networking sites and e-learning sites become the day-to-day communication agents of the young, it is vital for state education to maximize such learning opportunities and incorporate them into the curriculum. Because of its flexibility and student-centered focus on autonomy, the project-based approach offers a means of achieving this goal and of relieving the ever-increasing burden on the teacher. At present such an approach must fit into the restrictions of a high-stakes, competitive learning environment which has been shown to be ineffective in terms of achieving its own goals as well as those of employers and students (Gardner, 1993, p. 3). While it is to be hoped therefore, that education reform will eventually lead to a system in which highly qualified teachers are allowed to satisfy curriculum goals according to their own methods and philosophies, as in Finland (Finch, 2009), it is up to the 'ingenious educator' to make the most of opportunities such as those offered by the project-based approach, in order to satisfy the goals of the National Curriculum (UNESCO, 2006). As Stoller (2002) points out: 
Although project work may be easier to implement in second language settings because of more readily available content resources, teachers in foreign language settings have already proven that with adaptation and creativity, the project approach can be successful and rewarding for teachers and students alike. (Stoller, 2002, p. 117)

\section{References}

Beckett, G. H. \& Slater, T. (2005). The project framework: A tool for language, content and skills integration. ELT Journal, 59(2), 108-116. http://dx.doi.org/10.1093/eltj/cci024

Dryden, G. \& Vos, J. (2005). The new learning revolution. Stafford, UK: Network Educational Press Ltd.

Finch, A. E. (2001a). A formative evaluation of a task-based conversation English program. PAC Journal, 1(1), 125-146.

Finch, A. E. (2001b). The non-threatening learning environment. Korea TESOL Journal, 4(1), 133-158.

Finch, A. E. (2007). A project-based Freshman English program: Methods and implications. Foreign Languages Education. 14(3), 21-47.

Finch, A. E. (2009). European language education models: Implications for Korea. English Teaching, 64(4), 95-122.

Finch, A. E. (2010). A task-based university EFL program in Korea: Design, implementation and formative evaluation. Saarbrücken, Germany: Lambert Academic Publishing.

Finch, A. E. \& Hyun, T. D. (2000a). Tell Me More! Seoul: Hakmunsa Press.

Finch, A. E. \& Hyun, T. D. (2000b). The Way Ahead. Seoul: Hakmunsa Press.

Finch, A. E. \& Sampson, K. T. (2001). Portfolios and projects: The understanding crisis. Proceedings of the KOTESOL 2001 International Conference.

Finch, A. E. \& Sampson, K. T. (2004). It’s Up to You! Seoul: Chonghap Publishing Co.

Gardner, H. (1983). Frames of mind: The theory of Multiple Intelligences. New York: Basic Books.

Gardner, H. (1993). The unschooled mind: How children think and how schools should teach. London: Fontana Press.

Gee Choi-Wan, (2006). The traditional education of Korea. Seoul: EWHA Womans University Press.

Graddol, D. (2007). English next: Why global English may mean the end of 'English as a foreign language'. British Council. Retrieved September 4, 2011, from the World Wide Web: http://www.britishcouncil.org/learning-research-english-next.pdf.

Hashimoto, N. \& Fukuda, S. (2011). Reaching for their own goals: A more democratic classroom. The Language Teacher $35(1), 17-22$.

Hicks, D. (1994). Preparing for the future: Notes and queries for concerned educators. WWF-UK: Adamantine Press.

Kang, Shin-who. (2008). Hagwon may extend operation hours. Korea Times. Retrieved August 31, 2011, from the World Wide Web: http://www.koreatimes.co.kr/www/ news/ nation/2008/06/117_25589.html.

Kim, See-Bong. (June 26, 2005). Gathering Clouds. Korea Times. Retrieved August 31, 2011, from the World Wide Web: http://times.hankooki.com/.

Kroeker, R. H. (2009). The reality of English conversation classes: A study in a South Korean university. MA dissertation: University of Birmingham, CELS. Retrieved August 20, 2011, from the World Wide Web: http://www.asian-efl-journal.com/ Thesis/Thesis-Kroeker.pdf.

Krishnamurti, J. (1981). Education and the significance of life. New York: HarperCollins Publishers.

Larsen-Freeman, D. (2008). Complex systems and Applied Linguistics. Oxford: Oxford University Press.

Legutke, M. \& Thomas. H. (1991). Process and experience in the language classroom. Harlow: Longman.

McGovern, J. (1995). Changing paradigms: The project approach. Paper presented at the International Conference on Language in Development. Bali, Indonesia.

McLuhan, M., \& Fiore, Q. (1967). The medium is the massage. New York: Bantam books.

Mok, Ka-Ho, (2006). Education reform and education policy in East Asia. Abingdon, UK: Routledge.

Moon, Gwang-lip, (2009). Statistics paint Korean picture. Korea JungAng Daily.

Pearson Longman (2007). Teacher's guide to the Common European Framework. Retrieved August 20, 2011, from the 
World Wide Web: http://www.pearsonlongman.com/ae/cef/cefguide.pdf

Postman, N. (1995). The end of education: Redefining the value of school. New York: Alfred A. Knopf.

Spanos, W. V. (1985). The Apollonian investment of modern Humanist education: The examples of Matthew Arnold, Irving Babbitt, and I. A. Richards (Part Two). Cultural Critique, (2), 105-134. http://dx.doi.org/10.2307/1354203

Sterling, S. (2002). Sustainable education: Re-visioning learning and change. Totnes, Devon: Green Books Ltd.

Stoller, F. L. (2002). Project work: A means to promote language and content. In J. C. Richards \& W. A. Renandya (Eds.) Methodology in language teaching: An anthology of current practice, (pp. 107-120). Cambridge: Cambridge University Press. http://dx.doi.org/10.1017/CBO9780511667190.016

UNESCO (2006). World data on education: Republic of Korea. Retrieved August 20, 2011, from the World Wide Web: http://www.ibe.unesco.org.

\section{Notes}

Note 1. "We look at the present through a rear-view mirror. We march backwards into the future" (McLuhan \& Fiore, 1967).

Note 2. Italics in the original text.

Note 3. This approximation of initial Freshman English levels refers to overall proficiency. Most students are more proficient in reading and listening (e.g. B1 level) than in reading and writing, due to the nature of the exams for which they have prepared.

Note 4. Figures released by Statistics Korea in December 2009, show that "The number of hagwons, or private education institutes, rose 49 times between 1970 and last year, from 1,421 to 70,213" (Moon Gwang-lip, 2009). The Korea Times (2008) also quotes figures from the Korean Statistics Information Service: "Last year 77 percent of students received private education paying on average 220,000 won per month; 89 percent of elementary school students, 75 percent of middle school students and 55 percent of high school students" (Kang Shin-who, 2008). In the words of Kim, See-bong, the owner of such an institute, "Children from nursery school to high school go to five or six hagwons (private institutions) a week. Some take in as many as nine. When they come back home, they still have to prepare for the schoolwork" (Kim, 2005).

Note 5. This situation promises to change with the new National English Ability Test (NEAT), currently scheduled for implementation in 2015 or 2016.

Note 6. Gardner points out that even the most successful students (success being defined as attendance at prestigious schools, high grades, high test scores, excellent references from teachers, etc.) "typically do not display an adequate understanding of the materials and concepts with which they have been working" (1993, p. 3).

Note 7. The use of the term 'autocratically' refers to one of the three main teaching styles as explained in the first paragraph of section 3.4, but also refers to the teacher-centered nature of secondary test-preparation classes.

Note 8. The analogy of strange attractors (Larsen-Freeman, 2008) is particularly apt, since it describes not only the movement of policy reform in and around these four policy points, but it also implies that the same path is never repeated and that while generalizations may be made in terms of overall tendencies, exact delineation of this movement is unpredictable and dependant on complex variables.

Note 9. Kroeker (2009) offers a comprehensive survey of English education policy in Korea over recent decades, for which reason the interested reader is referred to this source for further details.

Note 10. It is notable that in the university at which the author currently (2011) teaches, courses are now being offered which focus on the sort of learning and listening strategies needed by students taking courses in which the teaching medium is English. These courses are extremely popular and point to an increased use of English for Academic Purposes (EAP) in the university and in Korea.

Note 11. These project packs consisted of: News project, Chat Show project, Presentation project, Drama project, Job Search project, Commercials (advertising) project, Meetings project, and Elections (public speaking) project.

Note 12. The Workbook was piloted in 2003 and the revised version published in 2004.

Note 13. These project packs consisted of: My Culture project, Drama project, Computers and Technology project, Film Festival project, TV News, and Global Issues project. 
Note 14. The Workbook was eventually put online and can be accessed at http://www.finchpark.com/books/u2u/. The Teacher's Resources are available at http://www.finchpark.com/books/u2u/cj/cj.htm.

Note 15. Interviews and questionnaires were carried out, but the results have since been mislaid.

Note 16. The philosophy behind a project-based approach is often seen as unfamiliar or impractical by teachers, so that a well-constructed teacher-support system is needed if the program is to succeed. The Workbook and the online Teacher's Resources (plus suggested lesson plans) attempted to provide such a structure, though an additional orientation period was also found to be necessary.

Note 17. These online resources were posted on the university server and are no longer accessible. However, they represented a significant move by the teachers to own the program by becoming involved in its maintenance and improvement.

Note 18. The questionnaire items have been translated by the author from the original Korean.

Note 19. "iEARN is working in South Korea with YES International to involve schools throughout the peninsula. One Korean teacher has conducted research on how collaborative project-based learning can be an effective tool in language instruction. (...) YES International is implementing the NSLI-Y Program for high school students. iEARN-Korea has also translated the iEARN Project Book into Korean" (http://www.iearn.org/country/iearn-south-korea).

Table 1. Number of guided teaching hours needed to fulfill the aims of each CEFR level, as recommended by the Association of Language Testers of Europe (Pearson-Longman 2007)

\begin{tabular}{|l|l|}
\hline A1 & Approximately $90-100$ hours \\
A2 & Approximately $180-200$ hours \\
B1 & Approximately $350-400$ hours \\
B2 & Approximately $500-600$ hours \\
C1 & Approximately $700-800$ hours \\
C2 & Approximately $1,000-1,200$ hours \\
\hline
\end{tabular}

Table 2. Survey results of questions 1 and 2 (Hashimoto \& Fukuda, 2011, p. 21)

\begin{tabular}{|l|c|c|c|c|c|c|}
\hline & \multicolumn{3}{|c|}{ Q1: Interest } & \multicolumn{3}{c|}{ Q2: Active Participation } \\
\hline & Democratic Course & Course A & Course B & Democratic Course & Course A & Course B \\
\hline Strongly agree & $50.0 \%$ & $27.5 \%$ & $14.3 \%$ & $80.0 \%$ & $35.0 \%$ & $31.0 \%$ \\
\hline Agree & $30.0 \%$ & $27.5 \%$ & $33.3 \%$ & $17.5 \%$ & $42.5 \%$ & $45.2 \%$ \\
\hline Neither & $22.5 \%$ & $45.0 \%$ & $35.7 \%$ & $2.5 \%$ & $22.5 \%$ & $19.0 \%$ \\
\hline Strongly disagree & $0.0 \%$ & $0.0 \%$ & $9.5 \%$ & $0.0 \%$ & $0.0 \%$ & $0.0 \%$ \\
\hline
\end{tabular}

*The Democratic Course used the project syllabus of locations 2 and 3.

Table 3. Survey results of questions 3 and 4 (Hashimoto \& Fukuda, 2011, p. 21)

\begin{tabular}{|l|c|c|c|c|c|c|}
\hline & \multicolumn{3}{|c|}{ Q3: Achievement } & \multicolumn{3}{c|}{ Q4: Satisfaction } \\
\hline & Democratic Course & Course A & Course B & Democratic Course & Course A & Course B \\
\hline Strongly agree & $65.0 \%$ & $40.0 \%$ & $14.3 \%$ & $45.0 \%$ & $25.0 \%$ & $11.9 \%$ \\
\hline Agree & $25.0 \%$ & $32.5 \%$ & $28.6 \%$ & $42.5 \%$ & $32.5 \%$ & $33.3 \%$ \\
\hline Neither & $10.0 \%$ & $27.5 \%$ & $38.1 \%$ & $15.0 \%$ & $35.0 \%$ & $38.1 \%$ \\
\hline Disagree & $2.5 \%$ & $0.0 \%$ & $9.5 \%$ & $2.5 \%$ & $7.5 \%$ & $11.9 \%$ \\
\hline Strongly disagree & $0.0 \%$ & $0.0 \%$ & $9.5 \%$ & $0.0 \%$ & $0.0 \%$ & $4.8 \%$ \\
\hline
\end{tabular}

*The Democratic Course used the project syllabus of locations 2 and 3. 